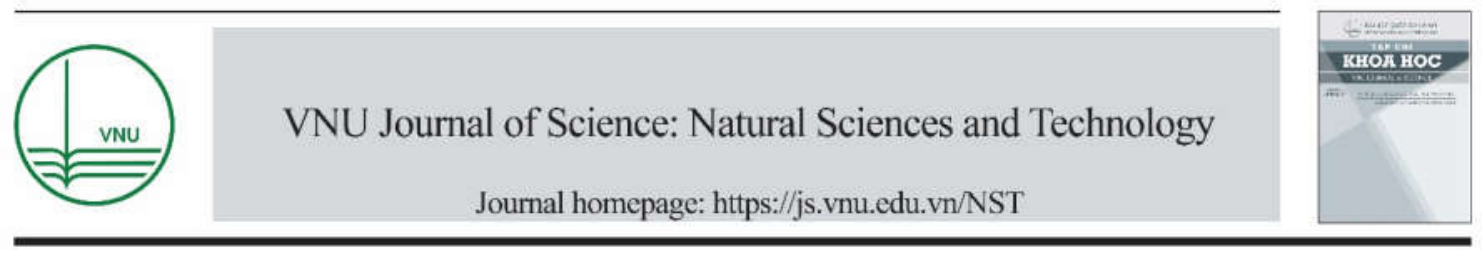

Original Article

\title{
Distribution and Toxic Equipvalent Assessement of Polycyclic Aromatic Hydrocarbons (Pahs) in Particulate Matter Emmited from Rice Straw Open Field Burning in Hanoi
}

\author{
Pham Chau Thuy ${ }^{1, *}$ and Le Huu Tuyen ${ }^{2}$ \\ ${ }^{1}$ Vietnam National University of Agriculture, Trau Quy, Gia Lam, Ha noi 131001, Vietnam \\ ${ }^{2}$ VNU University of Science, 334 Nguyen Trai, Hanoi 11400, Vietnam \\ Received 10 November 2020 \\ Revised 17 February 2021; Accepted 28 February 2021
}

\begin{abstract}
This study investigated the distribution and toxic equipvalent assesment of PAHs in particulate matter emitted from the open field burning of rice straw in Hanoi. Fine particles (PM2.5) was collected using a MiniVol TAS device (TAS-5.0, 4998, TAS, Airmetrics, USA) and the total suspended particles (TSP) was collected using a high-volume sampler Staplex (120H Staplex, 23759N, USA). PAHs in particulate matter were analyzed by HPLC-FL with fluorescent detector. The results showed that 4-ring PAHs were dominant in particles emitted from rice straw burning, especially the most abundant PAHs was Flu: 57,8 $\square$ 37,1 and 64,8 $\square$ 34,9 $\mu \mathrm{g} / \mathrm{g}$ in PM2.5 and TSP, respectively. However, the accumulation of PAHs with a higher rings number, especially the percentage of $\mathrm{BaP}$ in total 9PAHs in PM2.5 emitted from rice straw open burning was 2 times higher than that in the background samples, while the ratio of BaP in total 9PAHs in TSP from burning smoke is smaller than that of background samples. The carcinogenic potential of fine particles emitted from rice straw open burning calculated by BaPeq are 20 times higher than that of the background sample. Although the concentration of atmospheric particles - bound $\mathrm{BaP}$ in the present study $(1,0 \square 0,8 \mathrm{ng} / \mathrm{m} 3)$ is lower than that in urban and traffic areas, the average value of $\mathrm{BaP}$ is still 8,7 times higher than the value recommended by the WHO. The results of this study show a picture of the toxic levels of atmospheric particles and particles emitted from rice straw open burning, providing clearer evidence to understand the adverse effects of rice straw open burning on atmospheric environment and health effect.
\end{abstract}

Keywords: Rice Straw Open Burning, Polycyclic Aromatic Hydrocarbons (Pahs), Fine Particles (PM2.5), Total Suspended Particles (TSP), Toxic Equivalent Factor (TEF)

\footnotetext{
${ }^{\star}$ Corresponding Author.

Địa chỉemail: pcthuy@gmail.com,pcthuy@vnua.edu.vn lehuutuyen@hus.edu.vn
}

https://doi.org/10.25073/2588-1140/vnunst.5192 


\title{
Phân bố và độc tính tương đương của các hợp chất hydro cacbon thơm đa vòng (pahs) trong bụi phát thải từ đốt rơm sau thu hoạch tại Hà Nội
}

\author{
Phạm Châu Thuỳ 1,*, và Lê Hữu Tuyến ${ }^{2}$ \\ ${ }^{1}$ Học viện Nông nghiệp Việt Nam, Trâu Quỳ, Gia Lâm, Hà nội, Việt Nam \\ ${ }^{2}$ Truờng Đại học Khoa học Tụ nhiên, Đại học Quốc gia Hà Nội
}

Nhận ngày 10 tháng 11 năm 2020

Chỉnh sửa ngày 17 tháng 02 năm 2021; Chấp nhận đăng ngày 28 tháng 02 năm 2021

\begin{abstract}
Tóm tắt: Nghiên cứu điều tra sự phân bố về hàm lượng và đánh giá độc tính tương đương của các hợp chất PAHs trong bụi phát thải từ quá trình đốt rơm sau thu hoạch tại Hà nội. Bụi mịn (PM2.5) được lấy bằng thiết bị lưu lượng nhỏ MiniVol TAS (TAS-5.0, 4998, TAS, Airmetrics, USA) và bụi tổng (TSP) được lấy mẫu bằng thiết bị lưu lượng lớn (120H Staplex High-Vol sampler, $23759 \mathrm{~N}$, USA). PAHs trong bụi được phân tích bằng thiết bị sắc ký lỏng hiệu nâng cao với đầu dò huỳnh quang (HPLC-FL). Kết quả phân tích cho thấy các PAHs 4 vòng chiếm ưu thế trong bụi phát thải từ đốt rơm, đặc biệt Flu có hàm lượng cao nhất: $57,8 \square 37,1$ và $64,8 \square 34,9 \mu \mathrm{g} / \mathrm{g}$ trong bụi mịn và bụi tổng, tương ứng. Tuy nhiên, tỉ lệ $\%$ của các $\mathrm{PAHs}$ có số vòng cao hơn, đặc biệt là $\mathrm{BaP}$ (benzo[a]pyrene) trong tổng số $9 \mathrm{PAHs}$ trong bụi mịn phát thải từ đốt rơm lớn hơn so với tî̉ lệ trong mẫu nền, trong khi ở bụi tồng thì tỉ lệ \% $\mathrm{BaP}$ trong mâ̂u đốt nhỏ hơn so với mẫu nền. Kết quả đánh giá tiềm nâng gây ung thư của bụi mịn phát thải từ đốt rơm tính theo $\mathrm{BaP}$ tương đương $(\mathrm{BaPeq})$ cao gấp 20 lần so với mẫu nền. Nồng độ $\mathrm{BaP}$ trong không khí trong vụ Xuân tại khu vực nghiên cứu $(1,0 \square 0,8 \mathrm{ng} / \mathrm{m} 3)$ mặc dù thấp hơn so với BaP trong bụi tại các khu vực đô thị, giao thông, nhưng giá trị trung bình vẫn cao hơn 8,7 lần so với khuyến cáo của tổ chức y tế thế giới WHO. Kết quả nghiên cứu cho thấy bức tranh về mức độ độc của bụi trong không khí và bụi phát thải từ đốt rơm, làm bằng chứng rõ hơn về tác hại của việc đốt rơm rạ đối với ô nhiễm môi trường và sức khoẻ của người dân.
\end{abstract}

Tư khóa: Đốt rơm hở, hydrocarbon thơm đa vòng (PAHs), Bụi mịn (PM2.5), tổng bụi lơ lửng (TSP), hệ số độc tương đương (TEF)..

\section{1. Đặt vấn đề}

Đốt rơm rạ sau thu hoạch ngoài đồng ruộng vẫn là biện pháp phổ biến của bà con nông dân Việt nam nhằm dọn sạch đồng ruộng để chuẩn bị cho vụ mùa tiếp theo. Biện pháp này vẫn được xem là biện pháp đơn giản, nhanh chóng nhất được nông dân sử dụng mặc dù đã có nhiều biện pháp khuyến khích như trồng nấm, ủ làm phân compost, chế biến làm nhiên liệu đốt...Vẫn còn

\footnotetext{
${ }^{*}$ Corresponding Author.

Địa chỉ email: pcthuy@gmail.com, pcthuy@vnua.edu.vn lehuutuyen@hus.edu.vn
}

https://doi.org/10.25073/2588-1140/vnunst.5192 hiện tượng một số vùng ngoại ô ở Hà nội thu rơm đốt để lấy tro bán cho bà con nông dân làm phân bón. Cây lúa vẫn là cây lương thực chủ đạo của Việt Nam, nên lượng rơm rạ tạo ra vẫn tương đối lớn. Hiện tượng đốt rơm rạ vẫn xảy ra ở nhiều nơi, không chỉ Hà nội mà các tỉnh khác trên toàn

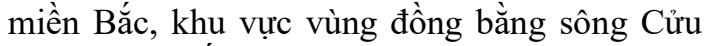
Long. Việc đốt rơm rạ đã tạo ra một lượng khói đặc quánh bao trùm một vùng rộng lớn, làm giảm 
tầm nhìn, nguy cơ gây mất an toàn giao thông, làm chất lượng không khí giảm đi một cách đáng kể [1]. Các chất ô nhiễm nằm trong khói thải từ việc đốt rơm rạ đã được rất nhiều nghiên cứu khảo sát bao gồm các loại khí gây hiệu ứng nhà kính như $\mathrm{CO}_{2}, \mathrm{CH}_{4}, \mathrm{NOx}$, các hydrocarbon không phải methan (NMHC), các hợp chất hữu cơ dễ bay hơi (VOC), các kim loại nặng và các hydrocarbon thơm đa vòng (PAHs) [2 - 5].

PAHs (Polycyclic aromatic hydrocarbons) là những chất gây ô nhiễm phổ biến trong môi trường được hình thành từ các quá trình đốt cháy không hoàn toàn và quá trình nhiệt phân của các vật chất hữu cơ và nhiên liệu hóa thạch [6]. PAHs là các hydrocarbon thơm đa vòng, công thức cấu tạo có ít nhất 2 vòng benzene, và trong phân tử chỉ chứa nguyên tố carbon và hydro. Có hàng trăm $\mathrm{PAHs}$ riêng rẽ được phát thải vào môi trường không khí. Theo cục bảo vệ môi trường Mỹ (USEPA), có 16 PAHs điển hình có tính độc cao và cần được nghiên cứu chúng nhiều hơn [7]. Mỗi PAH có thể tồn tại trong không khí ở pha khí hoặc hấp phụ trên các hạt bụi (pha hạt) tùy thuộc vào tính chất vật lý và hóa học chúng. Những PAHs có cấu trúc phân tử ít hơn 4 vòng benzene được tìm thấy nhiều ở pha khí, trong khi đó các PAHs có cấu trúc phân tử nhiều hơn 4 vòng benzene đa số hấp phụ trên các hạt bụi. Các PAHs có số vòng cao hơn (trên 5 vòng) là các chất có khả năng gây ung thư, đột biến gen cao. Mức đô độc hại của các $\mathrm{PAHs}$ đã được tổ chức quốc tế nghiên cứu về ung thư IARC phân loại theo nhóm, trong đó có 3 nhóm mạnh nhất bao gồm: Nhóm 1: chắc chắn gây ung thư cho con người, nhóm $2 \mathrm{~A}$ : hầu như chắc chắn gây ung thư cho con người và nhóm $2 \mathrm{~B}$ : có thể sẽ gây ung thư cho con người, khi bị phơi nhiễm $[8,9]$.

Ô nhiễm bụi là vấn đề đang được quan tâm của rất nhiều nhà khoa học và người dân bởi tác hại của nó đến sức khoẻ con người. Tổ chức $\mathrm{y}$ tế thế giới đã xếp bụi mịn $\left(\mathrm{PM}_{2.5}\right)$ vào nhóm 1 (nhóm chắn chắn gây ung thư cho con người). Các PAHs chứa trong bụi chính là một trong những tác nhân gây nên tính độc của bụi, đặc biệt là Benzo $[a]$ pyrene $(\mathrm{B} a \mathrm{P})$. $\mathrm{B} a \mathrm{P}$ là hydrocarbon thơm 5 vòng nhưng có tính độc nhất trong số các
PAHs tự nhiên, nó đã được tổ chức ung thư quốc tế xếp vào nhóm $1[8,9]$.

Gần đây, một số nghiên cứu định lượng các hợp chất PAHs từ đốt sinh khối trong nông nghiệp nói chung và từ đốt rơm nói riêng đã được thực hiện tại một số nước Đông Nam Ả [4, 10 12]. Hiện nay có một số nghiên cứu về ô nhiễm không khí từ đốt rơm rạ ở Việt Nam, trong đó chủ yếu tập trung vào kiểm kề phát thải $[1,13$, 14]. Một số nghiên cứu về PAHs trong không khí khu vực nông thôn, giao thông và đô thị đã được thực hiện tại việt $\operatorname{Nam}[5,15,16-19]$. Hiền và cs, 2013 khảo sát phân bố về kích thước và nguồn gốc của các PAHs trong bụi tại các địa điểm gồm tầng hầm bãi giữ xe, ven đường và không khí xung quanh ở thành phố Hồ Chí Minh [18]. Hoàng và cs 2019 phân tích hàm lượng và đánh giá mức độ ô nhiễm của các PAHs trong bụi lắng trong nhà và trên mặt đường tại Hà nội [19]. Tuy nhiên khả năng ảnh hưởng của bụi lắng trong không khí đến hệ hô hấp con người không đáng lo ngại bằng bụi lơ lửng và bụi mịn trong không khí. Việc xác định mức độ gây ung thư của các PAHs trong bụi trong không khí tại Hà nội cũng như bụi phát thải từ quá trình đốt rơm là các nghiên cứu chưa được đánh giá. Do đó nghiên cứu khảo sát sự phân bố, mức độ ô nhiễm và độc tính của các $\mathrm{PAHs}$ trong bui phát thải từ đốt rơm tại Hà Nội là rất cần thiết, nhằm cung cấp thông tin hữu ích, làm cơ sở dữ liệu cho các nghiên cứu xác định độc tính của bụi đối với con người và các nghiên cứu tiếp theo.

\section{Phương pháp nghiên cứu}

\subsection{Lựa chọn địa điểm lấy mẫu}

Nghiên cứu lựa chọn 14 cánh đồng trên 2 huyện Hoài Đức và Gia Lâm, thành phố Hà Nội làm các địa điểm lấy mẫu bụi. Các vị trí lấy mẫu được lựa chọn sao cho phải nằm ở giữa cánh đồng, cách xa nguồn đường và các nguồn dân sinh khác nhằm loại bỏ ảnh hưởng từ những nguồn thải khác. Tuy nhiên vị trí lấy mẫu cũng phải thuận tiện trong việc vận chuyển và lắp đặt các thiết bị lấy mẫu. Các cánh đồng này đều được 
gặt bằng máy gặt đập liên hợp, nên rơm và gốc rạ được tách thành hai phần rõ ràng trên mặt ruộng. Rơm được phơi khô tự nhiên trên các cánh đồng. Các thí nghiệm được thực hiện trên các giống lúa phổ biến trong các vụ canh tác.

\subsection{Phương pháp lấy mẫu bụi và xác định khối luợng bui}

Nghiên cứu thực hiện lấy mẫu bụi phát sinh từ quá trình đốt rơm trên các cánh đồng trong hai mùa vụ từ năm 2016 - 2018, vụ mùa gặt vào tháng 10 - 11 hàng năm và vụ xuân gặt vào tháng 6 - 7 hàng năm. Bố trí thí nghiệm được thực hiện dựa trên các nghiên cứu đã tiến hành tại Thái Lan [3 - 4]. Thí nghiệm được tiến hành trên hai loại mẫu: mẫu nền được thực hiện trước khi đốt rơm và mẫu đốt nhằm xác định sự khác nhau về phân bố hàm lượng PAHs trong bụi trong không khí (mẫu nền) và hàm lượng PAHs trong bụi từ đốt rơm (mẫu đốt rơm). Thời gian lấy mẫu nền là 2 tiếng, khoảng thời gian này đủ để thu khối lượng bụi thích hợp nhằm xác định thành phần $\mathrm{PAHs}$ trong bụi. Việc xác định vị trí lấy mẫu nền và mẫu đốt dựa trên xác định hướng gió chủ đạo của thời điểm lấy mẫu và phải có tính đại diện. Các thiết bị lấy mẫu bụi được đặt tại vị trí cố định cách đám cháy khoảng từ $4-5 \mathrm{~m}$ theo hướng gió, nhằm tránh ảnh hưởng của nhiệt độ của ngọn lửa. Thời gian lấy mẫu đốt dao động trong khoảng $20-40$ phút tuỳ theo khối lượng rơm được đốt. Việc lấy mẫu tại thời điểm đốt rơm được bắt đầu từ khi ngọn lửa ổn định cho đến khi đám cháy kết thúc. Bụi $\mathrm{PM}_{2.5}$ được lấy bằng thiết bị MiniVol TAS (TAS-5.0, 4998, TAS, Airmetrics, USA) với lưu lượng $5 \mathrm{~L} /$ phút theo phương pháp $\mathrm{AS} / \mathrm{NZS}$ 3580.9.7:2009 và bụi TSP được lấy bằng thiết bị lấy mẫu thể tích lớn Staplex (120H Staplex High-Vol sampler, $23759 \mathrm{~N}, \mathrm{USA}$ ) với lưu lượng $1000 \mathrm{~L} /$ phút theo TCVN 5067:1995. Thiết bị lấy mẫu bụi được đo cùng với các thiết bị đo vi khí hậu bao gồm: nhiệt độ, độ ẩm, tốc độ gió. Các thông số này được đo
5 phút một lần đối với mẫu đốt và 10 phút một lần đối với mẫu nền.

Giấy lọc sau khi lấy mẫu bụi được được đưa vào bình hút ẩm 24 giờ và đặt trong môi trường ổn định có nhiệt độ $\left(25 \pm 2^{\circ} \mathrm{C}\right)$ và độ ẩm không khí $(60 \pm 5 \%)$, sau đó được cân nhằm xác định khối lượng bụi thu được. Khối lượng bụi thu được là chênh lệch khối lượng của giấy lọc trước và sau khi lấy mẫu, có tính đến cả mẫu đối chứng và mẫu hiện trường. Mỗi loại giấy lọc và mỗi lô giấy lọc cần lấy một số mẫu đối chứng và mẫu hiện trường.

\subsection{Phuoong pháp chiết rút và phân tích $P A H s$}

Giấy lọc trước và sau khi lấy mẫu đều được đưa vào bình hút ẩm $24 \mathrm{~h}$ trước khi cân trong môi trường cân. Mẫu bụi được bọc trong giấy nhôm, bảo quản trong túi kín và giữ trong tủ lạnh ở $-20^{\circ} \mathrm{C}$ cho đến khi phân tích. Mẫu sau đó được chiết rút và phân tích PAHs tại phòng thí nghiệm của Đại học Kanazawa, Nhật Bản. Các PAHs trên giấy lọc bụi được chiết xuất siêu âm hai lần với $10 \mathrm{~mL}$ dichloromethane $(\mathrm{DCM})$ trong 15 phút. Dung dịch nội chuẩn (hỗn hợp $\mathrm{B} a \mathrm{~A}-d 12$ và $\mathrm{B} a \mathrm{P}-d 12$ (lần lượt là 60 và $33 \mathrm{ng} / \mathrm{mL}$ ) được sử dụng để định lượng PAH. Sau khi thêm $60 \mu \mathrm{L}$ dimethyl sulfoxide (DMSO) vào dịch chiết, DCM trong dung dịch chiết được bay hơi hoàn toàn bằng thiết bị cô quay. $\mathrm{PAH}$ trong cặn được hòa tan trong $150 \mu \mathrm{L}$ ethanol, dịch chiết được lọc qua màng lọc ly tâm (Centricut, đường kính 0,2 $\mu \mathrm{m})$. Bước này được lặp lại hai lần. Một phần dung dịch $(110 \mu \mathrm{L})$ của dung dịch cuối cùng được phân tích bằng thiết bị sắc ký lỏng hiệu năng cao HPLC với đầu dò huỳnh quang (HPLCFL). Chi tiết phương pháp phân tích được mô tả tại Boogla et al., 2017 [20]. Các PAHs được phân tích bao gồm: fluoranthene (Flu), pyrene (Pyr), benz[a] anthracene (BaA), chrysene (Chr), benzo[b]fluoranthene (BbF), benzo[k]fluoranthene $(\mathrm{BkF})$, benzo[a]pyrene $(\mathrm{BaP}), \quad \operatorname{dibenz}[\mathrm{a}, \mathrm{h}]$ anthracene $(\mathrm{DBA})$ và indeno[1,2,3-cd]pyrene (IDP). 

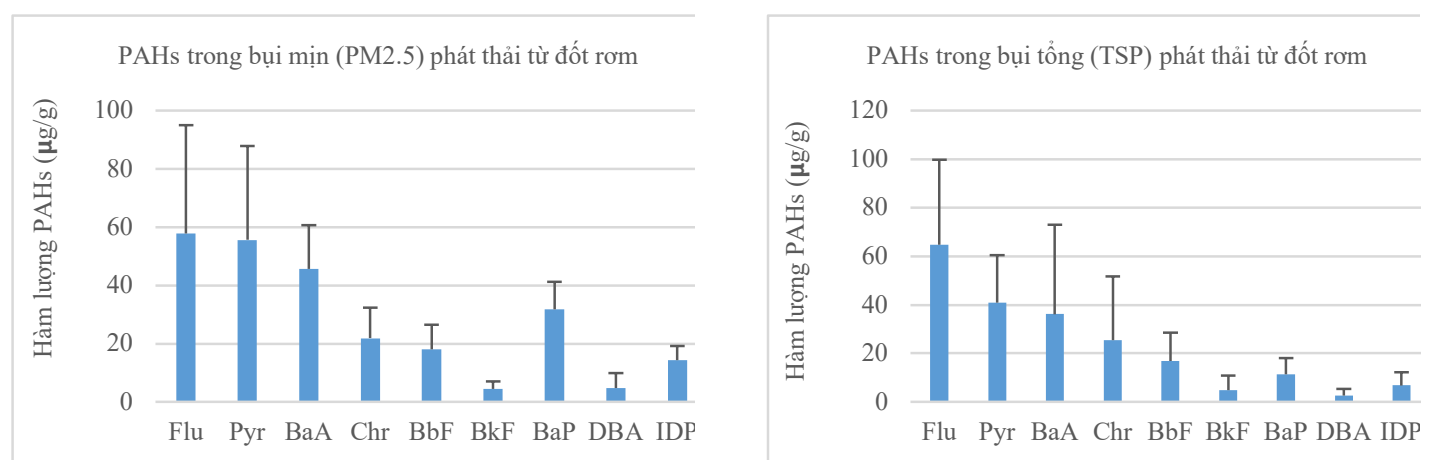

Hình 1: Phân bố hàm lượng PAHs trong bụi phát thải từ đốt rơm

\section{Kết quả và thảo luận}

\subsection{Hàm lượng PAHs trong bụi phát thải tù̀ quá trình đốt rơm}

Hàm lượng các hợp chất PAHs trong bụi phát thải từ quá trình đôt rơm được mô tả trong Hình 1. Hàm lượng các $\mathrm{PAHs}$ trong bụi $\mathrm{PM}_{2.5}$ và TSP phát thải từ quá trình đốt rơm có sự khác biệt. Trong số 9 PAHs được phân tích trong bụi, hàm lượng của Flu và Pyr chiếm đa số trong cả bụi mịn $\left(\mathrm{PM}_{2.5}\right)$ và bụi tổng (TSP). Flu trong bụi mịn có hàm lượng $(57,8 \pm 37,1 \mu \mathrm{g} / \mathrm{g})$ không có sự khác biệt đáng kể so với bụi tổng $(64,8 \pm 34,9$ $\mu \mathrm{g} / \mathrm{g})$. Tuy nhiên trong số các PAHs phân tích thì $\mathrm{PAH} 5$ vòng $(\mathrm{BaP})$ và $\mathrm{PAH} 6$ vòng (IDP) có hàm lượng trong bụi mịn lớn hơn hẳn so với hàm lượng trong bụi tổng. Đặc biệt $\mathrm{BaP}$ là chất có độ độc được IARC xếp vào nhóm 1 (chắc chắn gây ung thư khi bị phơi nhiễm ở một ngưỡng nhất định), có hàm lượng $31,7 \pm 9,4 \mu \mathrm{g} / \mathrm{g}$ trong bụi mịn, trong khi $\mathrm{BaP}$ ở bụi tổng có hàm lượng 11,3 $\pm 6,7 \mu \mathrm{g} / \mathrm{g}$. Đây cũng là một kết quả cần chú ý về tính độc của bụi từ đốt rơm. PAHs phát thải từ quá trình đốt cháy các vật chất hữu cơ nên các hạt bụi phát thải từ các quá trình đốt cháy này lúc đầu là các hạt bụi mịn trong phạm vi kích thước $0,01-0,08 \mu \mathrm{m}[21]$. Tuy nhiên, sau khi phát thải, các hạt bụi "hạt nhân" (nuclei mode) ban đầu sẽ tích tụ với nhau tạo thành các hạt bụi lớn hơn với các kích thước khác nhau mà có thể gọi là bụi có kích thước tích luỹ (accumulation mode) và bụi thô (coarse fractions). PAHs có thể liên kết với hạt bụi lớn hơn thông qua quá trình gắn kết của các hạt bụi hạt nhân và quá trình bay hơi từ bụi mịn, sau đó ngưng tụ lại trên bụi thô. Sự phân bố của các PAHs trong không khí phụ thuộc vào tính chất hoá lý của chúng. Kết qủa các nghiên cứu trước đều cho thấy, các PAHs có số vòng cao hơn (5-6 vòng) có khả năng tập trung ở các hạt bụi mịn nhiều hơn do khối lượng phân tử lớn, áp suất bay hơi thấp nên khả năng ít bay hơn hơn, ít linh động hơn so với các PAHs 4 vòng [10]. Các PAHs 4 vòng sau khi phát thải ra từ nguồn đốt, chúng cũng bám vào các hạt bụi mịn trước tiên nhưng do khả năng linh động hơn, dễ bay hơn nên chúng sẽ bay hơi và bám trên 

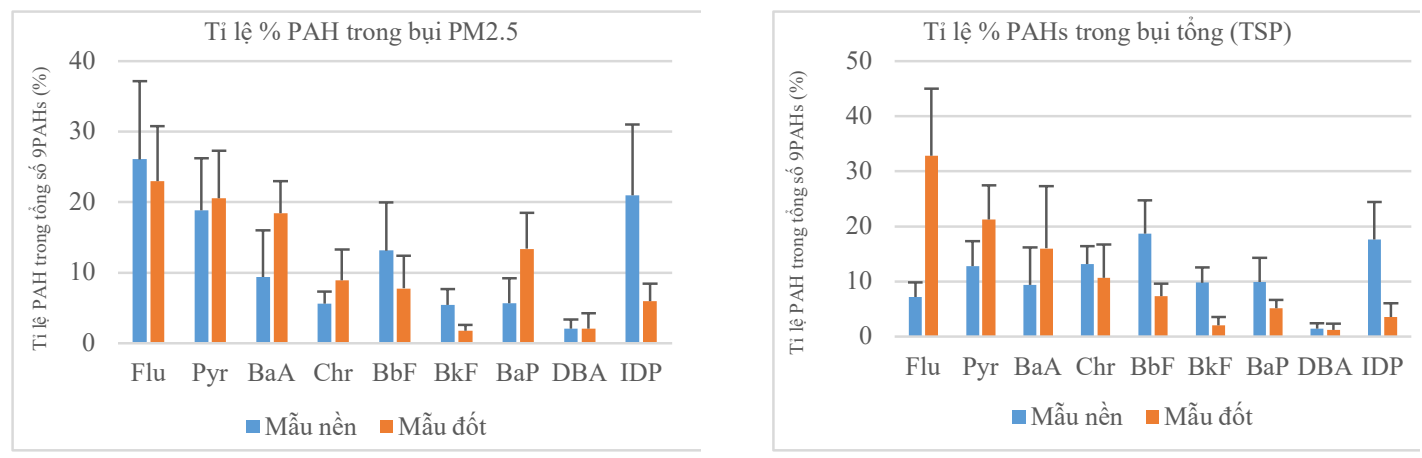

Hình 2. Phân bố tỉ lệ PAHs trong bụi phát thải từ đốt rơm

bụi thô, do đó chúng có mặt trong cả bụi mịn và bụi tổng có kích thước lớn hơn. Điều này giải thích cho kết quả trong số các PAHs có 4 vòng, Flu là chất có khối lượng phân tử bé nhất và áp suất bay hơi cao nhất nên nó có mặt nhiều nhất trong cả bụi mịn và bụi tổng. Trong khi hàm lượng các PAHs 5, 6 vòng có mặt trong bụi mịn trong khói đốt rơm nhiều hơn so với bụi tổng, đặc biệt là hàm lượng $\mathrm{BaP}$ và IDP và $\mathrm{BaA}$.

\subsection{Phân bố tỉ lệ PAHs trong mẫu nền và trong mẫu đốt rơm}

Nghiên cứu đã lấy mẫu bụi mịn và bụi tổng trong không khí trước khi có đốt rơm (mầu nền) và bụi phát thải trực tiếp từ quá trình đốt rơm (mẫu đốt) nhằm đánh giá sự đóng góp của hàm lượng PAHs trong bụi phát thải từ đốt rơm so với bụi trong không khí khi không có đốt rơm. Kết quả tỉ lệ \% về khối lượng của từng $\mathrm{PAHs}$ riêng lẻ trong tổng số 9PAHs phân tích trong từng loại bụi phát thải từ quá trình đốt rơm và từ mẫu nền được mô tả trong Hình 2. Kết quả cho thấy, trong số các $\mathrm{PAHs}$ phát thải từ đốt rơm, mặc dù $\mathrm{PAHs}$ 4 vòng là Flu và $P y r$ chiếm ưu thế trong cả mẫu nền và mẫu đốt, nhưng tỉ lệ $\%$ của $B a P$ và $B a A$ (13 và $18 \%$, tương ứng) trong bụi mịn của mẫu đốt là tăng lên đáng kể so với tỉ lệ trong mẫu nền (gấp khoảng 2 lần). Trong khi ở các hạt bụi lớn hơn (TSP) thì tỉ lệ đóng góp của Flu, Pyr là nhiều nhất ( 32,8 và $21,2 \%$, tương ứng), lớn hơn gấp 4,5 và 1,6 lần so với mẫu nền. Nhìn chung tỉ lệ phân bố PAHs trong mẫu nền và mẫu đốt có sự khác biệt đáng kể bởi sự thay đổi chủ yếu của Flu và $\mathrm{BaP}$, Flu tích luỹ trong khói đốt rơm nhiều nhất trong bụi tổng, còn $\mathrm{BaP}$ tích luỹ trong khói đốt rơm nhiều nhất ở bụi mịn.

\subsection{Tỉ lệ BaP trong các loại bụi khác nhau}

Kết quả cho thấy trong số các PAHs, tỉ lệ đóng góp của $\mathrm{B} a \mathrm{P}$ trong bụi mịn và bụi tổng có sự chú ý đáng kể. Kết quả này thể hiện rõ hơn ở Hình 3. Đối với bụi mịn, tî̉ lệ $\%$ của $\mathrm{B} a \mathrm{P}$ trong tổng số $9 \mathrm{PAHs}$ nằm trong bụi phát thải từ đốt rơm dao động từ $9,4-26,1 \%$, cao hơn rất nhiều so với mẫu nền (dao động từ $3,7-9,7 \%$ ) trong số 10 mẫu phân tích. Trong khi đó, tỉ lệ \% $\mathrm{BaP}$ trong tổng số 9 PAHs trong bụi tổng phát thải từ đốt rơm dao động trong khoảng $4-8 \%$ thấp hơn so với tỉ lệ $\% \mathrm{BaP}$ trong mẫu nền $(7-18 \%)$. Điều đó cho thấy khả năng tích luỹ của $\mathrm{BaP}$ trong bụi mịn cao hơn so với bụi tổng. Kết quả này hoàn toàn phù hợp với các nghiên cứu trước, các PAHs có số vòng cao sẽ tích luỹ ở các phần tử bụi mịn nhiều hơn so với bụi thô. Kết qủa này có thể giải thích sự tồn tại của $\mathrm{PAHs}$ trong không khí liên quan đến khối lượng phân tử của PAHs và áp suất hơi trong không khí. Các phân tử PAHs có khối lượng phân tử càng lớn thì càng khó bay hơi. PAHs 5, 6 vòng, cụ thể trong nghiên cứu này là $\mathrm{B} a \mathrm{P}$, có áp suất hơi thấp $\left(7,3 \times 10^{-7} \mathrm{~Pa}\right)$ và phân tử lượng lớn (252) so với PAHs 4 vòng (ví dụ Flu có khối lượng phân tử là 202 và áp 


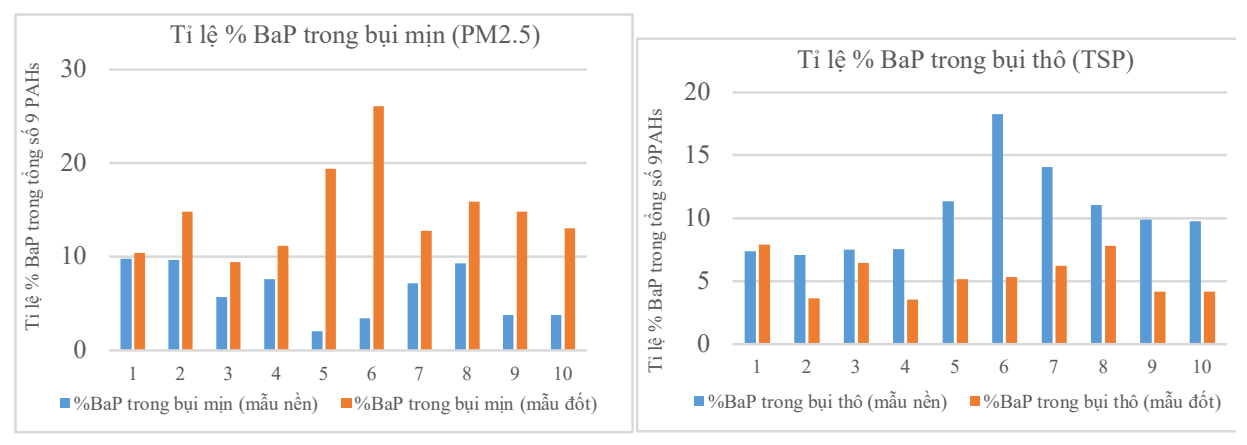

Hình 3. Phân bố hàm lượng $\mathrm{BaP}$ trong các loại bụi khác nhau.

suất hơi là $1,6 \times 10^{-2} \mathrm{~Pa}$. Sau khi liên kết với hạt bụi mịn các PAHs có khối lượng phân tử lớn hầu như không bay hơi. Do đó, chúng có xu hướng ở lại trong bụi mịn, làm cho nồng độ của các PAHs này có nhiều trong bụi mịn, ít hơn trong bụi thô. Điều này cũng thêm khẳng định thành phần PAHs trong bụi mịn và bụi tổng sẽ có sự khác biệt, trong đó $\mathrm{B} a \mathrm{P}$ trong bụi mịn từ quá trình đốt rơm đã có sự khác biệt đáng kể so với mẫu nền. Kết quả này cung cấp thông tin về đặc điểm phân bố các chất hydrocarbon thơm trong khói đốt rơm, đặc biệt sự đóng góp của $\mathrm{B} a \mathrm{P}$ trong bụi mịn.

\section{4. Đánh giá độc tính của PAHs trong bụi phát thải tù̀ đốt rơm}

Độc tính của bụi không chỉ phụ thuộc vào kích thước của hạt bụi mà còn phụ thuộc vào thành phần hoá học của hạt bụi. Một trong số đó là các hợp chất hydrocarbon thơm đa vòng PAHs. Xét trên quan điểm độc học, độc tính của hỗn hợp PAHs (đáng chú ý nhất là khả năng gây ung thư) cần được định lượng thông qua một chất tham chiếu và một bộ hệ số độc tương đương (TEF). Trong số các hợp chất PAHs, BaP được biết đến là một chất gây ung thư mạnh nhất và thường được sử dụng làm chất đánh dấu cho phơi nhiễm PAHs. BaP là chất được sử dụng phổ biến nhất trong các nghiên cứu về độc học của $\mathrm{PAHs}$ và thường được coi là chất có $\mathrm{TEF}=1$. Trong nghiên cứu này, chúng tôi tính toán độ độc tương đương của các $\mathrm{PAHs}$ so với $\mathrm{BaP}(\mathrm{BaPeq})$ sử dụng thang TEF đề xuất bởi Nisbet và LaGoy (1992) [22]. Trong các tiêu chuẩn quy định của các quốc gia cũng chọn chỉ số $\mathrm{BaP}$ để đánh gía mức độ ô nhiễm của các hợp chất PAHs. Để đánh giá tiềm năng gây ung thư của các PAH hấp phụ trên bụi trong không khí và trong khói đốt rơm, phương pháp tiếp cận sử dụng hệ số độc tương đương đã được chứng minh phản ánh độc tính tương đối của các PAH khác nhau một cách chính xác hơn. Tiềm năng gây ung thư của phơi nhiễm PAHs thông qua đường hô hấp được ước tính qua nồng độ của $\mathrm{BaP}$ tương đương $(\mathrm{BaPeq})$. Nghiên cứu đã tính toán hàm lượng $\mathrm{BaPeq}$ cho từng $\mathrm{PAH}$ riêng lẻ bằng cách nhân nồng độ của nó trong PM với hệ số TEF tương ứng của nó. Tiềm năng gây ung của tổng PAHs (tổng-BaPeq) trong từng loại bụi trong không khí (mâ̂u nền) và trong khói đốt rơm trong nghiên cứu này được tính theo tổng của $\mathrm{BaP}$ tương đương của $9 \mathrm{PAH}$ đã phân tích trong bụi. Hàm lượng $\mathrm{BaPeq}$ trung bình trong bụi $\mathrm{PM}_{2.5}$ của mẫu nền $(2,0 \pm 1,7$ $\mu \mathrm{g} / \mathrm{g}$ ) thấp hơn so với hàm lượng BaPeq trung bình trong bụi tổng $(7,1 \pm 5,5 \mu \mathrm{g} / \mathrm{g})$. Tuy nhiên sự sai khác này không có ý nghiã thống kê và BaP là chất đóng góp trung bình $59 \%$ ở cả bụi $\mathrm{PM}_{2.5}$ và bụi tổng đối với mẫu nền. Còn đối với mẫu đốt, BaP chiếm $78 \%$ độ độc tương đương của tổng $\mathrm{PAHs}$ đối với bụi $\mathrm{PM}_{2.5}$ và $62 \%$ đối với TSP. Thứ tự xếp hạng mức độ đóng góp tiềm năng gây ung thư của các $\mathrm{PAHs}$ từ cao đến thấp trong mẫu đốt là $\mathrm{BaP}, \mathrm{BaA}, \mathrm{BbF}, \mathrm{IDP}, \mathrm{BkF}$ trong khi đối với mẫu nền thì thứ tự đó là $\mathrm{BaP}$, IDP, $\mathrm{BbF}, \mathrm{BaA}$ và $\mathrm{BkF}$. Kết quả cho thấy độc tính tương đương $\mathrm{BaPeq}$ của các PAHs trong bụi ở 
mẫu đốt cao hơn rất nhiều so với mẫu nền. Đặc biệt đối với bụi mịn $\mathrm{PM}_{2.5}$, hàm lượng $\mathrm{BaPeq}$ trung bình của các $\mathrm{PAHs}$ trong bụi phát thải từ đốt rơm cao gấp 20 lần so với bụi trong không khí. Trong khi BaPeq của các PAHs trong bụi TSP phát thải từ đốt lớn hơn 2,5 lần so với mẫu nền. Điều đó chứng tỏ khi hít khói đốt rơm trong mùa đốt rơm, tiềm năng gây ung thư là rất cao. Đặc biệt bụi mịn là bụi dễ dàng đi sâu vào đường hô hấp hơn. Hơn nữa bụi càng nhỏ thì diện tích bề mặt riêng càng lớn, khả năng hấp phụ và giữ lại các PAHs có khả năng gây ung thư tốt hơn và ít có khả năng bay hơi hơn do đặc điểm lý hoá học của chúng, đó là các PAHs có 5, 6 vòng. Kết quả này cũng một phần giải thích cho khả năng gây ung thư của bụi mịn đã được đề cập đến nhiều nghiên cứu trước đây. Một số quốc gia và tổ chức đã thiết lập giới hạn nồng độ $\mathrm{BaP}$ trong không khí. Tổ chức y tế thế giới WHO khuyến nghị nồng độ $\mathrm{BaP}$ trong không khí an toàn ở mức dưới $0,12 \mathrm{ng} / \mathrm{m}^{3}$. Theo $\mathrm{WHO}$, nồng độ phơi nhiễm trong suốt vòng đời dẫn đến tỉ lệ rủi ro mắc ung thư là $1 / 10000,1 / 100000$ và $1 / 1000$ 000 tương ứng với nồng độ phơi nhiễm là 1.2 , 0,12 và $0.012 \mathrm{ng} / \mathrm{m}^{3}$ [23]. Nồng độ trung bình hàng năm của $\mathrm{BaP}$ tại nhiều trạm quan trắc trên thế giới vẫn ở trên mức tham chiếu này. Trong nghiên cứu này, nồng độ $\mathrm{BaP}$ trong bụi trong không khí tại vụ xuân là $1,0 \pm 0,8 \mathrm{ng} / \mathrm{m}^{3}$ cao hơn so với vụ mùa $\left(0,15 \pm 0,09 \mathrm{ng} / \mathrm{m}^{3}\right)$ và cao hơn gấp 8,7 lần so với tiêu chuẩn của WHO. Nồng độ $\mathrm{BaP}$ trong không khí của mẫu nền tại nghiên cứu này (khu vực nông thôn) cao hơn so với khuyến cáo của WHO. Tuy nhiên, nó còn thấp hơn nhiều so nồng độ BaP trong không khí tại các vị trí khu vực giao thông và đô thị của Hà Nội và thành phố Hồ Chí Minh. Nồng độ $\mathrm{BaP}$ tại vị trí giao thông của Hà Nội dao động trong khoảng 0,11 $2,3 \mathrm{ng} / \mathrm{m}^{3}$ [17]. Nồng độ BaP trong không khí tại thành phố Hồ Chí Minh dao động trong khoảng $0,11-1,3 \mathrm{ng} / \mathrm{m}^{3}$ tại khu vực trường Đại học Khoa học tự nhiên, đại học Quốc gia TPHCM và 0,15 - 2,0 tại khu vực dân cư [16]. Như vậy có thể thấy nồng độ $\mathrm{BaP}$ trong không khí tại các khu vực của Hà nội, thành phố Hồ Chí Minh có nồng độ $\mathrm{BaP}$ đều cao hơn so với khuyến cáo của WHO. Đây là thông tin cần thiết khi đánh giá chất lượng không khí và ảnh hưởng của bụi tới sức khoẻ. Đánh giá độ độc của bụi trong khuôn khổ của nghiên cứu này thông qua đánh giá tiềm năng gây ung thư dựa trên phân tích các chất PAHs và áp dụng hệ số độc tương đương, do đó kết quả chỉ phản ánh một phần nhất định của độ độc. Thực tế còn rất nhiều các hợp chất khác có độc tính cao đóng góp vào độ độc của bụi như các dẫn xuất methyl, hydroxyl, nitro của PAHs và các chất dị vòng khác. Vì vậy nghiên cứu này có thể mở ra các hướng tiếp cận mới như kết hợp phân tích hóa học với phân tích sinh học nhằm đánh giá ảnh hưởng của hỗn hợp chất nằm trong bụi đối với con người là rất cần thiết. Kết quả này là bằng chứng giúp bà con nông dân nhận thức tính độc hại của bụi phát thải từ đốt rơm, làm ngăn chặn, giảm thiểu biện pháp đốt rơm phổ biến mà bà con nông dân hiện nay đang sử dụng.

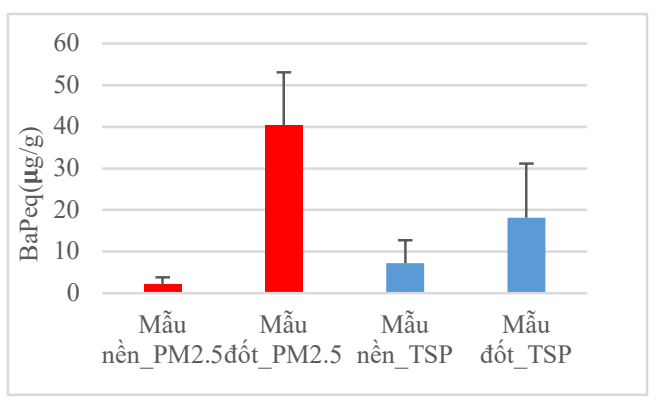

Hình 4. Độ độc tương đương so với $\mathrm{B} a \mathrm{P}$ của PAHs trong các loại bụi khác nhau

\section{Kết luận}

Kết quả khảo sát hàm lượng PAHs trong bụi phát thải từ đốt rơm cho thấy các PAHs 4 vòng như Flu và Pyr là hai PAHs chiếm tỉ lệ ưu thế trong số 9 PAHs phân tích. Hàm lượng của Flu trong bụi mịn và bụi tổng lần lượt là $57,8 \pm 37,1$ và $64,8 \pm 34,9 \mu \mathrm{g} / \mathrm{g}$, tương ứng. Tuy nhiên hàm lượng $\mathrm{BaP}$ và $\mathrm{IDP}$ là các $\mathrm{PAHs}$ trong bụi mịn lớn hơn hẳn so với trong bụi tổng. $\mathrm{BaP}$ có hàm lượng trong bụi mịn là $31,7 \pm 9,4 \mu \mathrm{g} / \mathrm{g}$, cao hơn trong bụi tổng $(11,3 \pm 6,7 \mu \mathrm{g} / \mathrm{g})$. Tỉ lệ phân bố về khối lượng của các chất PAHs 5 vòng và 6 vòng, đặc 
biệt là $\mathrm{BaP}$ và IDP trong bụi mịn $\mathrm{PM}_{2.5}$ cao hơn so với bụi tổng TSP. Tỉ lệ \% BaP trong tổng số 9PAHs trong bụi mịn phát thải từ đốt rơm dao động từ 9,4-26,1\% trong khi tỉ lệ này dao động từ $4-8 \%$ trong bụi tổng. Kết quả cũng cho thấy tỉ lệ đóng góp của $\mathrm{BaP}$ trong bụi mịn phát thải từ đốt rơm có sự chênh lệch đáng kể so với mẫu nền. Đánh gía về tiềm năng gây ung thư của các PAHs trong bụi phát thải từ đốt rơm cho thấy, với tỉ lệ $\mathrm{BaP}$ cao trong khói đốt rơm dẫn đến tiềm năng gây ung thư tính theo $\mathrm{BaP}$ tương đương của bụi phát thải từ đốt rơm cao gấp 20 lần so với bụi trong không khí khi không có đốt rơm. So sánh nồng độ $\mathrm{BaP}$ trong không khí tại khu vực nghiên cứu cho thấy mặc dù nồng độ $\mathrm{BaP}$ trong mẫu nền tại khu vực nghiên cứu thấp hơn so với các khu vực giao thông và dân cư của Hà nội và thành phố Hồ Chí Minh, nhưng nó vẫn cao hơn tiêu chuẩn WHO 8,7 lần và cao hơn tiêu chuẩn của một số nước Châu Âu, Trung Quốc. Đây là những thông tin hữu ích cần phổ biến, tuyên truyền cho bà con nông dân tác hại của việc đốt rơm, đồng thời giúp các nhà quản lý môi trường có các biện pháp mạnh mẽ hơn trong việc kiểm soát phát thải từ việc đốt rơm rạ sau thu hoạch ngoài đồng ruộng.

\section{Lò̀i cảm ơn}

\section{Nghiên cứu được tài trọ̣ bởi Quỹ Phát triển Khoa học và Công nghệ Quốc gia Việt Nam - NAFOSTED (đề tài mã số 104.99-2015.88).}

\section{Tài liệu tham khảo}

[1] H. A. Le, N. T. T. Hanh, L. T. Linh, Estimated Gas Emission from Burning Rice Straw in Open Fields in Thai Binh Province. VNU Journal of Science: Earth and Environmental Science, Vol. 29, 2013, pp. 26-33. (in Vietnamese).

[2] E. Sanchis, M. Ferrer, S. Calvet, C. Coscoll, V. Yus, M. Cambra, Gaseous and Particulate Emission Profiles during Controlled Rice Straw Burning, Atmos. Environ., Vol. 98, 2014, pp. 2531 , https://doi.org/10.1016/j.atmosenv.2014.07.062.

[3] T. K. O. Nguyen, B. T. Ly, D. Tipayarom, B. R. Manandhar, P. Prapat, C. D. Simpson, L. J. S. Liu, Characterization of Particulate Matter Emission from Open Burning of Rice Straw, Atmos. Environ., Vol. 45, 2011, pp. 493-502. http://doi.org/10.1016/j.atmosenv.2010.09.023.

[4] T. K. O. Nguyen, A. Tipayaroma, B. T. Ly, D. Tipayaroma, C. D. Simpson, D. Hardie, L. J. S. Liu, Characterization of Gaseous and SemiVolatile Organic Compounds Emitted from Field Burning of Rice Straw, Atmos. Environ., Vol. 119, 2015, pp. 182-191.

[5] C. T. Pham, Y. Boongla, T. D. Nghiem, H. T. Le, N. Tang, A. Toriba, K. Hayakawa, Emission Characteristics of Polycyclic Aromatic Hydrocarbons and Nitro-Polycyclic Aromatic Hydrocarbons from Open Burning of Rice Straw in the North of Vietnam, International Journal of Environmental Research and Public Health, Vol. 16, No. 13, 2019, pp. 2343. https://doi.org/10.3390/ijerph16132343

[6] W. F. Rogge, L. M. Hildemann, M. A. Mazurek, G. R. Cass, B. R. Simo, Sources of Fine Organic Aerosol. 2. Noncatalyst and Catalyst-Equipped Automobiles and Heavy-Duty Diesel Trucks, Environ. Sci. Technol., Vol. 27, 1993, pp. 636-651.

[7] USEPA Provisional Guidance for Quantitative Risk Assessment of Polycyclic Aromatic Hydrocarbons Provisional Guidance for Quantitative Risk Assessment of Polycyclic Aromatic Hydrocarbons, Environmental Protection Agency Publishing House, 1993.

[8] European Environment Agency, Annual Mean Bap Concentrations in 2018, Annual Mean BaP Concentrations in 2018, Available online: https://www.eea.europa.eu/data-andmaps/figures/annual-mean-bap- concentrations-in4 (accessed on 12 February 2021).

[9] International Agency for Research on Cancer, Working Group on the Evaluation of Carcinogenic Risks to Humans. Some Non-Heterocyclic Polycyclic Aromatic Hydrocarbons and Some Related Exposuresitle. In IARC Monogr. Eval. Carcinog. Risks Hum., 2010.

[10] H. Keshtkar, L. L. Ashbaugh, Size Distribution of Polycyclic Aromatic Hydrocarbon Particulate Emission Factors from Agricultural Burning. Atmos. Environ., Vol. 41, 2007, pp. 2729-2739. doi:10.1016/j.atmosenv.2006.11.043.

[11] T. Korenaga, X. Liu, Z. Huang, The Influence of Moisture Content on Polycyclic Aromatic Hydrocarbons Emission During Rice Straw Burning, Chemosph - Glob. Chang. Sci., Vol. 3, 2001, pp. 117-122.

H. Lu, L. Zhu, N. Zhu, Polycyclic Aromatic Hydrocarbon Emission from Straw Burning and 
the Influence of Combustion Parameters, Atmos. Environ., Vol. 43, No. 4, 2009, pp. 978-983. https://doi.org/https://doi.org/10.101 6/j.atmosenv.2008.10.022

[12] N. M. Dung, Estimated Gas Emission from Rice Straw Open Buring in Field at Red River Delta area, J. Sci. Dev., Vol. 10, 2012, 190 -198.

[13] K. Lasko, K. Vadrevu, Improved Rice Residue Burning Emissions Estimates: Accounting for Practice Specific Emission Factors in Air Pollution Assessments, Environ. Pollut., Vol. 236, 2018, pp. 795-806.

https://doi.org/10.1016/j.envpol.2018.01.098

[14] L. H. Tuyen, N. M. Tue, G. Suzuki, K. Misaki, P. H. Viet, S. Takahashi, S. Tanabe, Aryl Hydrocarbon Receptor Mediated Activities in Road Dust from a Metropolitan Area, Hanoi, Vietnam: Contribution of Polycyclic Aromatic Hydrocarbons (PAHs) and Human Risk Assessment, Sci. Total Environ, Vol. 491, 2014, pp. 246-254. https://doi.org/10.1016/j.scitotenv.2014. 01.086.

[15] T. T. Hien, L. T. Thanh, T. Kameda, N. Takenaka, H. Bandow, Distribution Characteristics of Polycyclic Aromatic Hydrocarbons with Particle Size in Urban Aerosols at the Roadside in Ho Chi Minh City, Vietnam, Atmos. Environ., Vol. 41, 2007, pp. 1575-1586. https://doi.org/10.1016/j.atmosenv. 2006.10.045.

[16] C. T. Pham, T. Kameda, A. Toriba, N. Tang, K. Hayakawa, Characteristics of Atmospheric Polycyclic Aromatic Hydrocarbons and Nitropolycyclic Aromatic Hydrocarbons in HanoiVietnam, as a Typical Motorbike city, Polycyclic Aromatic Compounds, Vol. 32, No. 2, 2012, pp. 296-312.

https://doi.org/10.1080/10406638.2012.679015
[17] T. T. Hien, H. V. An, Size Distribution and Resources of PAHs in Atmospheric Particulate Matters in Ho Chi Minh city, Journal of Science \& Technology Development, Vol. 16, No. 3, 2013, 18-26. (in Vietnamese)

[18] H. Q. Anh, S. Takahashi, D. T. Thao, N. H. Thai, P. T. Khiet, N. T. Q. Hoa, L. T. P. Quynh, L. N. Da, T. B. Minh, T. M. Tri, Analysis and Evaluation of Contamination Status of Polycyclic Aromatic Hydrocarbons (PAHs) in Settled House and Road Dust Samples from Hanoi. VNU Journal of Science: Natural Sciences and Technology, Vol. 35, No. 4, 2019, 63-71, https://doi.org/10.25073/2588-1140/vnunst.4943. (in Vietnamese)

[19] Y. Boongla, W. Orakij, Y. Nagaoka, N. Tang, K. Hayakawa, A. Toriba, Simultaneous Determination of Polycyclic Aromatic Hydrocarbons and Their Nitro-Derivatives in Airborne Particulates by Using Two-Dimensional High-Performance Liquid Chromatography with on-Line Reduction and Fluorescence Detection. Asian J. Atmos. Environ., Vol. 11, 2017, pp. 283299.

[20] B. F. Pitt, J. N. Pitts, Chemistry of the Upper and Lower Atmosphere: Theory, Experiments, and Applications, Academic Press, London, 2000, pp. $438-439$.

[21] I. C. T. Nisbet, P. K. LaGoy, Toxic Equivalency Factors (TEFs) for Polycyclic Aromatic Hydrocarbons (PAHs). Regulatory Toxicology and Pharmacology, Vol. 16, 1992, pp. 290- 300.

[22] WHO, WHO Guidelines for Indoor Air Quality: Selected Pollutants (2010). World Health Organization Regional Office for Europe.

[23] https://www.euro.who.int/_data/assets/pdf_file/0 009/128169/e94535.pdf (accessed on 12 February 2021). 